\title{
ESTUDO DE CASO DOS FATORES RESPONSÁVEIS PELA DEMANDA DE MANUTENÇÃO DA ESCOLA DE MINAS/UFOP
}

\author{
NOVAIS, DULCELENE \\ Arquiteta e Urbanista \\ Universidade Federal de Ouro Preto \\ Minas Gerais; Brasil \\ arqdulcegamarano@gmail.com \\ NOGUEIRA, MARCELA \\ Arquiteta e Urbanista \\ Universidade Federal de Ouro Preto \\ Minas Gerais; Brasil \\ marcela.nogueira@aluno.ufop.edu.br \\ BRIGOLINI, GUILHERME \\ Engenheiro Civil, D.Sc \\ Universidade Federal de Ouro Preto \\ Minas Gerais; Brasil \\ guilhermebrigolini@ufop.edu.br
}

\author{
LINHARES, NARA \\ Engenheiro Civil, M.Sc \\ Universidade Federal de Ouro Preto \\ Minas Gerais; Brasil \\ linhares.nara@gmail.com \\ ELOI, FERNANDA \\ Engenheiro Civil \\ Universidade Federal de Ouro Preto \\ Minas Gerais; Brasil \\ fernandaeloi94@gmail.com \\ MENDES, JÚLIA \\ Engenheiro Civil, D.Sc \\ Universidade Federal de Ouro Preto \\ Minas Gerais; Brasil \\ julia.mendes@ufop.edu.br
}

\section{RESUMO}

Muitos problemas relacionados ao desempenho das edificações são comumente identificados nos edifícios públicos, que em sua maioria, se encontram em constantes reparos. A manutenção é um conjunto de ações que tem como objetivo manter as condições mínimas de desempenho de uma edificação para que sua utilização atenda ao fim para o qual foi destinada, mas a frequente e precoce demanda dessa manutenção pode sugerir outros fatores responsáveis pelos problemas encontrados, como escolha inadequada de materiais ou erro de concepção. Nesse cenário, o presente trabalho realiza um estudo de caso na Escola de Minas da Universidade Federal de Ouro Preto, a fim de identificar esses fatores responsáveis a partir de uma inspeção e coleta de dados e entrevista com os responsáveis pelo projeto, execução e manutenção da edificação. Foram identificados vários motivadores para a demanda frequente por manutenção, como a falta de um sistema de gestão para este fim, alterações de uso, projeto sem consultoria dos autores originais e a lei de licitações que impõe o menor preço aos componentes construtivos.

Palavras-chave: desempenho de edificações, manutenção das edificações, patologias das edificações.

\begin{abstract}
Many problems related to building performance are commonly identified in public buildings, most of which are under constant repair. Maintenance is a set of actions that aim to maintain the minimum performance conditions to comply with the construction purpose; but a frequent and early demand for maintenance may suggest other factors responsible for the problems, such as improper choice materials or design error. In this scenario, the present work conducts a case study at the Escola de Minas of the Universidade Federal de Ouro Preto, in order to identify these responsible factors from an inspection, data collection and interview with those responsible for the project, execution and maintenance of the building. Several reasons for the frequent demand for maintenance were identified, such as the lack of a management system for this purpose, changes of use and design without consulting the original authors and the bidding law that imposes the lowest price on the building components.
\end{abstract}

Keywords: performance of buildings, maintenance of buildings, pathologies of buildings. 


\section{INTRODUÇÃO}

Sabe-se que a principal função de uma edificação é servir de abrigo, protegendo usuários e recursos. A arquitetura, responsável pelo projeto das edificações, vai além da etapa da concepção de representação gráfica para atender beleza e funcionalidade. Assim sendo, só é verdadeiramente belo e funcional aquilo que também é durável e seguro. Segundo Neves (2011), um projeto arquitetônico é um plano técnico temporário de empreendimento que tem como objeto a construção, envolvendo diferentes atividades no decorrer de sua vida útil. Cabe aos responsáveis técnicos zelarem por todas as fases do empreendimento, ou seja, concepção, execução, utilização e manutenção.

Considera-se um projeto bem-sucedido quando em sua concepção e execução prevê-se bom desempenho, segurança e conforto. Escolhas criteriosas viáveis e adequadas de materiais, de execução, de detalhamentos e de soluções construtivas corretas, aliadas a manutenção preventiva e corretiva das edificações ao longo dos tempos tornam-se de suma importância para manter a vida útil destas edificações. De acordo com Villanueva (2015) considera-se hoje que a manutenção é cada vez mais um elemento decisivo na gestão dos edifícios e um peso importante em termos das despesas globais ao longo da vida útil dos mesmos, suas instalações e equipamentos, sendo a única ferramenta para aumentar seu tempo de vida, impedindo o envelhecimento precoce das edificações.

A NBR 14037 (ABNT, 2011) cita como uma das principais causas do descaso com as edificações a falta de manutenção em si, uma vez que muitos usuários entendem como objetivo final o processo construtivo inicial e se esquecem das manutenções ao longo da vida útil da edificação. Esta inversão de valores, derivada da lógica da mercadoria, coloca o real motivo pelo qual a edificação foi construída em detrimento, pois coloca a satisfação das necessidades dos usuários em segundo plano. Com o passar do tempo, os inconvenientes resultantes da inexistência de atividades de manutenção preventivas e corretivas se tornam mais frequentes, e ameaçam o sentimento de segurança e satisfação dos usuários, causando perceptíveis manifestações patológicas (CASTRO, 2007).

Patologias das construções é o campo de estudo das origens, formas de manifestações, consequências e mecanismos de ocorrência das falhas e dos sistemas de degradação das estruturas (SOUZA e RIPPER, 1998). Conforme Dardengo (2010), são diversas as causas dos processos de deterioração dos elementos construtivos. Elenca-se como origens das manifestações: as ocorrências acidentais, as congênitas (derivadas de projetos errôneos), executivas (da má construção), do emprego de materiais inadequados e/ou fora das especificações técnicas, que na maioria das vezes são escolhidos sob o argumento de razões de ordem econômica e a falta de manutenção.

Guimarães (2018) destaca que a conservação de edificações públicas, no que tange a despesa monetária de desembolso, é baseada em três indicadores, a despesa de manutenção anual, o desempenho da edificação e a eficiência da manutenção. Tal conjunto de indicadores poderia fundamentar a tomada de decisão na área de logística governamental ou, precisamente, administração de edifícios públicos, assim como melhorar o planejamento e orçamento na Administração Pública.

Neste contexto, o presente trabalho investiga o estado de conservação do atual edifício da Escola de Minas (EM), instituição pública da Universidade Federal de Ouro Preto (UFOP), fundada em 1876 por Henri Gorceix e idealizada por Dom Pedro II. O prédio mais recente dessa instituição foi inaugurado em 1995 (LEMOS, 2013). Esta edificação foi projetada por quatro arquitetos, ex-alunos do curso de mestrado em Construções Metálicas da EM/UFOP (LEMOS, 2013): Eliana Magalhães Brandão de Oliveira, Fernando Murilo Gontijo Ramos, Marcus Vinícius Rios Meyer e Marco Aurélio Ferreira da Silva. O projeto foi feito a pedido do idealizador, o Prof. Antônio Maria Claret de Gouveia, e foi supervisionado por outros arquitetos e engenheiros da UFMG (UFOP, 1993).

Os sistemas do edifício da EM, como qualquer outro, possuem uma vida útil estimada. Porém, muitas vezes, principalmente nas instituições públicas, antes do término deste prazo, as edificações já apresentam manifestações patológicas, enfrentando desafios diários para manter um bom estado de conservação. A importância cultural da instituição UFOP e escassez das referências bibliográficas sobre a EM fundada em 1995 motivou a realização desse trabalho.

Dessa forma, o presente trabalho tem por objetivo fazer o diagnóstico do estado de conservação do edifício principal da EM ,Campus Morro do Cruzeiro, da UFOP. De posse dos levantamentos e classificações das patologias existentes, será possível para as partes interessadas entender as causas, principalmente aquelas ligadas à fase de projeto, fazer consultas e definir com maior facilidade as prioridades de reparos. 


\section{METODOLOGIA}

Como ferramenta inicial de investigação, foram levantados os dados da instituição por meio de plantas, fotos etc. Esses registros foram coletados na Prefeitura do Campus, no departamento do Instituto do Patrimônio Histórico e Artístico Nacional (IPHAN), no centro de Ouro Preto e no acervo da biblioteca da Escola de Farmácia/UFOP.

Na sequência, foi realizada uma vistoria in loco das manifestações patológicas existentes. As inspeções foram realizadas entre os meses de maio a dezembro de 2017, com maior concentração no período de junho a agosto. Realizou-se, também, o diagnóstico das manifestações patológicas existentes no edifício da EM, levando em conta o tipo de construção, observações climáticas e pesquisas anteriores.

Por fim, foram realizadas entrevistas com profissionais que estiveram e/ou ainda estão envolvidas no projeto, construção, expansões e manutenção do edifício. Diante dos poucos dados bibliográficos encontrados sobre o projeto da EM após 1993, ano da criação do projeto, as entrevistas dessas partes interessadas trouxeram informações relevantes para o entendimento da gestão de manutenções feitas no prédio assim como contexto histórico da instituição. Foram entrevistados 12 profissionais que contribuíram de algum modo para a obtenção de maiores informações.

\section{RESULTADOS E DISCUSSÕES}

\subsection{Estado de conservação do prédio da Escola de Minas}

A EM da UFOP é distribuída em 18 blocos, entre dois pátios internos. Os 18 blocos foram projetados e executados em diferentes anos e fases, o que ocorre frequentemente em obras públicas. O edifício é caracterizado pela presença de estrutura metálica em aço, com fechamento de alvenaria de tijolo aparente e vidros. Assim, observa-se que uma vasta gama de diferentes materiais se faz presente na composição da EM, como concreto armado, alvenaria, madeira e vidro, ligados diretamente à estrutura de aço.

A FIGURA 1 retrata a fachada da EM em diferentes épocas, separadas por 21 anos. Nota-se que a condição atual do prédio é bem diferente, como por exemplo, o forro em condição precária, apresentando desplacamento, o que por consequência levou à interdição da entrada principal por questões de segurança dos usuários da EM.

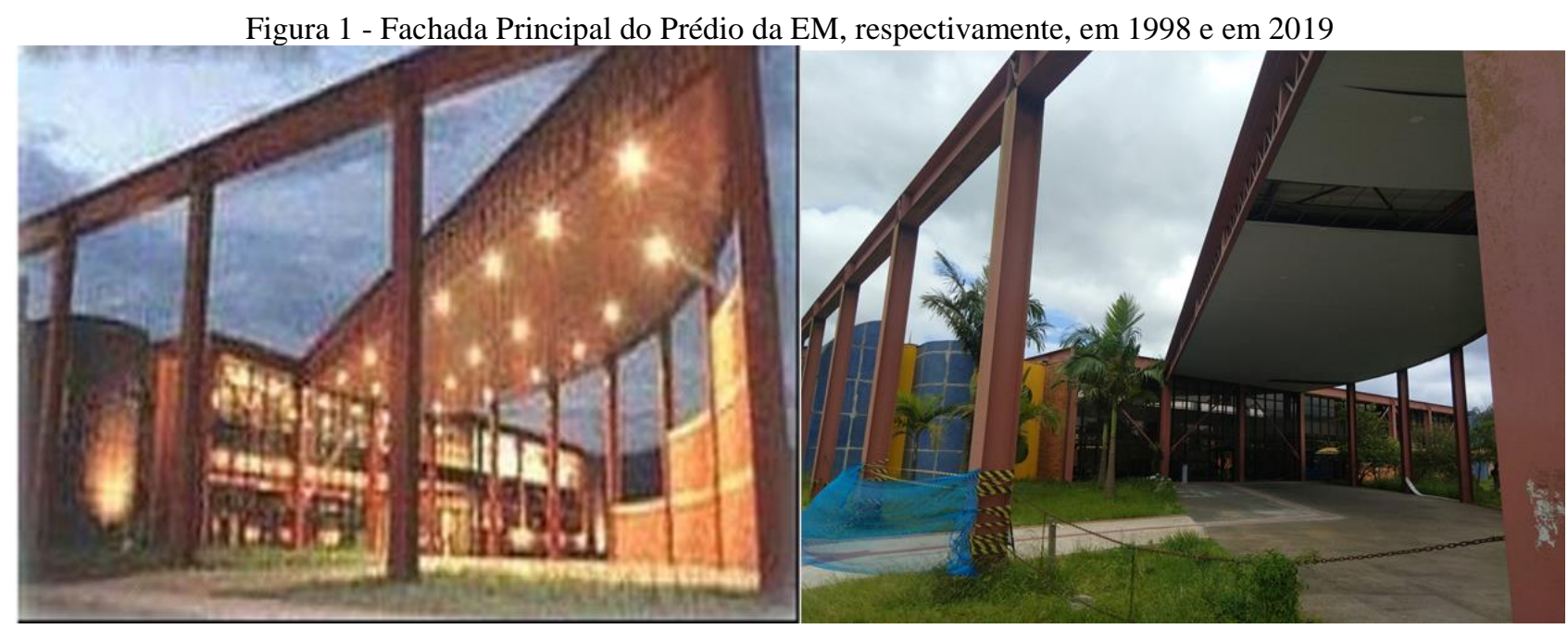

Fonte: Ribas, 2006 (esquerda) e Autores (direita).

Devido às diversas complexidades de projeto e aos diferentes materiais usados na construção do edifício da Escola de Minas, embora a as equipes de conservação sempre busquem diferentes alternativas para sanar os problemas construtivos, verificou-se problemas ao longo do tempo de utilização. Assim, a fim de entender a intensidade e gravidade das manifestações patológicas da EM, foram realizados uma inspeção e o mapeamento destas patologias. Os fenômenos mais comumente encontrados são: desgaste de pintura, trincas, infiltrações na cobertura e no revestimento, descascamentos de revestimentos, problemas nos fechamentos internos, manchas de infiltração, aparecimento de fungos e organismos 
biológicos, corrosão metálica, deformações das estruturas, umidade ascendente, erosão e descascamento dos tijolos, desgaste das películas de vidro, dentre outros. Observa-se que após 21 anos de ocupação, as patologias não chegam a comprometer estruturalmente a edificação, mas prejudicam seu desempenho e causam certo desconforto visual.

Observa-se pela FIGURA 2 algumas das manifestações patológicas observadas nas fachadas sul e norte da EM. No bloco intitulado 16, lado A, percebe-se desplacamento de revestimento. Parreira e Ramos, (2017) reforçam a importância da escolha correta de materiais cerâmicos de revestimento de acordo com sua classe e processo de fabricação, assim como no uso de argamassa apropriada, ajustada ao tipo de área de exposição, e juntas de dilatação. No bloco 11 percebe-se o vidro quebrado que acarretará problemas de vedação e desconforto térmico, além de perceptível desgaste da película do vidro. No Bloco 7, lado C, percebe-se bolores, eflorescência e trincas na superfície. Sobre o aparecimento de trincas, processo construtivo de manutenção difícil, segundo Macedo (2018) o aparecimento de fissuras e trincas em fachadas é resultado de diversos fatores, sendo os principais relacionados a má execução ou ausência do projeto de fachadas, causado pela movimentação do revestimento externo devido a variações climáticas. Para bloco 7, lado E, são observados bolores em vários pontos da fachada e vestígios de infiltração, visíveis pelo escurecimento do revestimento. Na imagem que representa o bloco 2, observa-se uma série de patologias no mesmo local, umidade ascendente, presença de vegetação, desgaste de pintura e corrosão galvânica. No bloco 6 percebe-se a corrosão galvânica mais uma vez, agora na estrutura metálica do prédio e finalmente o bloco 9 apresentando umidade ascendente, bolores e pontos de corrosão.

Parte dos problemas observados podem ser atribuídos à inadequação ou falta de manutenção e/ou limpeza, como acúmulo de sujidade com fezes de pombos, fim da vida útil das películas de vidros e ambientes propícios a proliferação de bolores e lodos. De forma geral, várias manifestações são atribuídas exposição às intempéries, principalmente à umidade, característica marcante da cidade de Ouro Preto. Diversas falhas também são possivelmente provenientes de erros de projeto e execução.

Figura 2 -Patologias observadas na Fachada Sul do Prédio da Escola de Minas, em 2017.

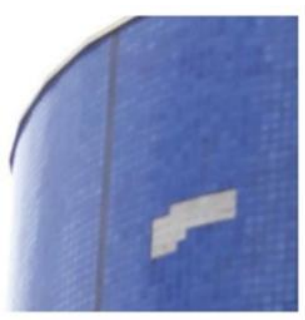

Bloco 16 lado A

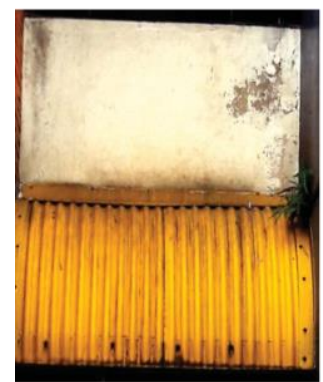

Bloco 2 Lado A

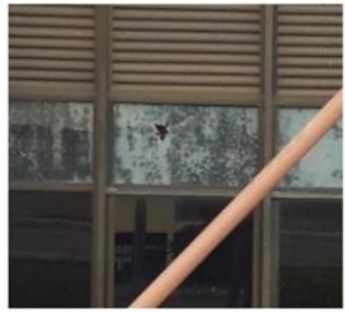

Bloco 11

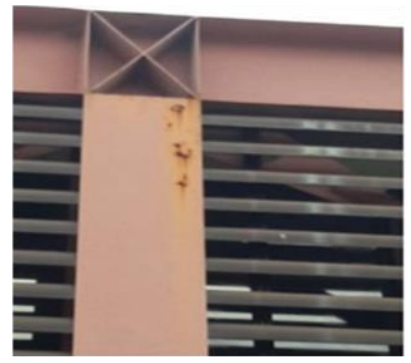

Bloco 6

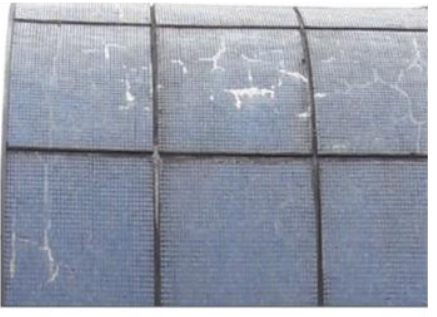

Bloco 7 Lado C

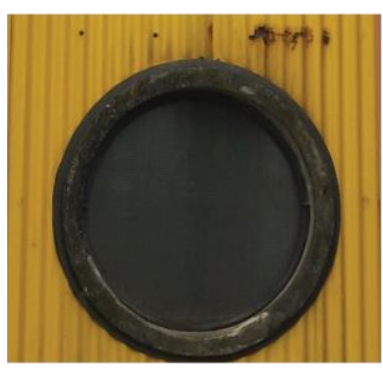

Bloco 9

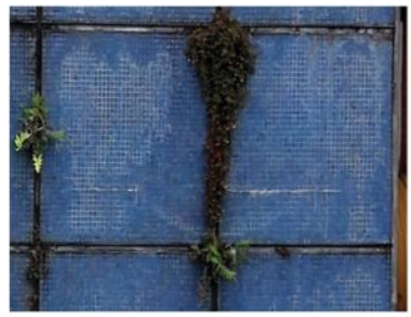

Bloco 7 Lado E

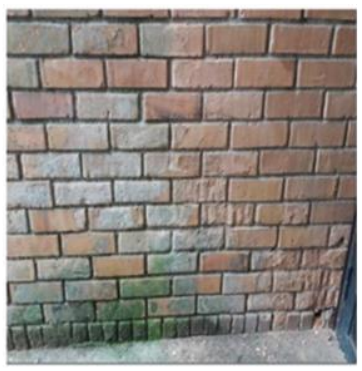

Bloco 9

Fonte: Autores 


\subsection{Da concepção do projeto à execução do ponto de vista das entrevistas com os envolvidos}

A EM já se estabeleceu em um prédio histórico, antigo Palácio dos Governadores na Praça Tiradentes de Ouro Preto, que hoje abriga um museu. Este antigo edifício não possibilitava expansões e apresentava difícil acesso para entrega de produtos e equipamentos, principalmente os de grande porte. Devido a um cenário político favorável da época, houve a possibilidade da concepção de um novo projeto e construção da nova EM no atual campus da UFOP, estudo de caso deste trabalho. De acordo com os engenheiros civis Antônio Maria Claret de Gouveia, diretor e professor do curso de mestrado em estruturas metálicas daquela época, e José Augusto Nunes Nogueira, responsável pela PRECAM, intensos debates ocorreram no período da definição do projeto em relação ao local de implantação, às escolhas dos materiais construtivos e à simplificação do projeto inicial.

Em entrevistas realizada com profissionais envolvidos neste projeto, como por exemplo o projetista e atual professor arquiteto urbanista da UFMG, Fernando Murilo Gontijo Ramos, relatou-se que desde o início, ele e sua equipe se preocuparam com o fator durabilidade em todas as etapas do projeto. Ele afirma ainda, que os projetistas se preocuparam "em evitar o menor grau de indigência possível que levasse acontecer patologias na edificação, principalmente, por ser um prédio público com poucos recursos financeiros sem possibilidades de manutenções constantes”. Entretanto, tanto Fernando Ramos quanto Antônio Claret afirmaram que após a aprovação do projeto e liberação dos recursos financeiros, os quatro arquitetos projetistas não participaram da etapa de execução do projeto elaborado.

O professor Fernando Ramos também afirmou que os maiores desafios enfrentados na concepção do projeto foram trabalhar o bloqueio de ruídos de chuva nos sheds da cobertura da biblioteca e a solução técnica dos problemas de ligações entre materiais diferentes, como a estrutura metálica e as alvenarias. José Augusto Nogueira apontou como preocupação possíveis patologias, que atualmente podem ser verificadas, como demonstrado na FIGURA 2, provenientes de escolhas de materiais inadequados e dessemelhantes.

Uma das principais patologias decorrentes do projeto foi relacionada ao sistema de cobertura do prédio. De acordo com o engenheiro civil da PRECAM, Neymar Camões de Moura, ao buscar esconder as telhas de folha de alumínio atrás dos perfis metálicos das vigas, a inclinação mínima aplicada e adotada em projeto, então sugerida por norma, não foi suficiente para evitar futuros danos de infiltração, não sendo eficaz para garantir o aspecto estético e esconder as telhas e também promover o perfeito escoamento de água das chuvas. Essa situação origina até hoje infiltrações e efeitos inconvenientes da ação do vento. Tal problema foi resolvido em dois blocos, onde os sistemas de cobertura sofreram intervenções, afirmou José Augusto Nogueira.

Sobre a estrutura metálica do prédio, Nogueira afirmou que entre o período de licitação e o início da obra houve uma mudança no plano econômico e de moeda no Brasil, durante o governo do presidente Itamar Franco. Esse fato fez com que as empresas licitadas pela UFOP aumentassem em $11 \%$ os valores dos produtos e de seus serviços. Devido ao teto do financiamento disponível, foi necessário "reduzir a espessura do aço e trabalhar dentro do mínimo possível".

Notou-se nas inspeções in loco, também é reforçado por Moura em entrevista, que a estrutura metálica da EM é esbelta e está dentro dos limites de segurança, porém se movimenta muito e os deslocamentos possibilitam maiores incidências de trincas. Para o engenheiro, uma das consequências da esbeltez das chapas de aço são as deformações de pequena intensidade nas abas, que podem ser vistas em vários perfis. Também existem casos de deformações maiores, como exemplificou: "lá tivemos deformações de quase 30 milímetros de flecha na viga, ninguém percebe porque tem forro".

O arquiteto projetista Fernando Ramos salientou que, embora não tenha descaracterizado quase nada do ponto de vista da arquitetura, na fase de detalhamento do projeto dificuldades financeiras provocaram alterações e exclusões em diferentes itens. Júlio de Barros do Nascimento, engenheiro civil e arquiteto do PRECAM, afirmou que a impossibilidade de prosseguir com a construção no tempo devido por falta de recursos favoreceu a maior incidência de patologias no prédio: "a fundação foi feita por uma empresa, a estrutura por outra, aí ficou só no esqueleto (...), então veio outra empresa [para continuar a execução], porque o dinheiro veio chegando aos poucos. Depois foi outra empresa que fechou [a obra]".

Para o professor Ernani Carlos de Araújo, ex-prefeito universitário e atual professor do departamento de engenharia civil da UFOP, "toda obra pública tem estes problemas financeiros que atrapalham qualquer projeto". Além disso, afirmou ele, não é raro, em uma obra pública, acontecer de arrecadarem financiamento na licitação para determinadas rubricas, e estes serem usados para outras. 
Por fim, tanto Nogueira quanto Claret concordaram que a administração gerencial da EM não deixa claro o que pretende ou o que será feito no tocante à manutenção prédio. Neste contexto, afirmou Nogueira, "se houve ou não recurso para manutenção, faltou uma definição clara de como deveria ser usado". Nogueira também afirmou que "dentro dos 36 anos que estive na UFOP, os diretores não foram incisivos (...) para que fosse feita uma devida manutenção, então a gente faz o que pode".

Neste âmbito, a PRECAM por volta de 2015 adquiriu o sistema de manutenção informatizada, mas encontra-se ainda sem um programa de manutenção definido, sem inspeções corriqueiras e com atividades predominantes de manutenções corretivas. Além disto, através dos dados da catalogação de solicitações realizadas até 2011, foi possível constatar que as solicitações eram feitas, genericamente, sem uma proposta de manutenção específica para cada prédio do Campus.

Observou-se por meio das entrevistas que houve poucas intervenções ao longo dos anos. A intervenção de maior relevância foi feita no sistema de cobertura em somente dois blocos, no ano de 2006. Nos anos 2012 e 2017 , foram realizados reparos de rebocos na parte interna nas caixas de escadas e rampa por causa de infiltração através das coberturas e dos revestimentos externos de pastilhas. O prédio foi parcialmente repintado entre os anos 2005 a 2006. Nesses períodos também foram colocados brises em algumas fachadas para amenizar a luz direta dentro dos aposentos do prédio.

Os entrevistados também demonstram preocupação com o atual cenário de contenção constante de custos vivido pelas universidades brasileiras, como a UFOP. Segundo Claret, “a fase atual é uma das piores para manter a conservação do prédio com manutenção desde a década de 80 ”.

\section{CONCLUSÕES}

Este trabalho buscou analisar os fatores responsáveis pelas principais manutenções no edifício da EM da Universidade Federal de Ouro Preto (UFOP). Para esse fim, foi realizada uma inspeção in loco para levantar o estado de conservação do prédio, levantamento de documentos referentes a etapa construtiva do prédio, além de entrevistas com os profissionais responsáveis por sua concepção, execução e manutenção.

O diagnóstico realizado mostra que a edificação em estudo não apresenta nenhum inconveniente de ordem estrutural observado, mas problemas construtivos surgiram em detrimento da falta de manutenção preventiva e corretiva adequada, como nos fechamentos, revestimentos, pintura etc., ao longo de seu uso. Para uma melhor conservação da edificação, manutenções periódicas e planejadas devem ser feitas, pois patologias estão em contínuo processo de avanço. Atualmente, as patologias que mais comprometem o desempenho da edificação são àquelas associadas à corrosão e à infiltração.

O manual de uso e conservação dos elementos construtivos das edificações torna-se fundamental e deveria ser utilizado, respeitando assim as periodicidades de manutenção sugeridas, assim como os programas de atividades e informações inerentes aos serviços a serem realizados, especificações dos materiais adequados para manutenção.

Ressalta-se que a EM é uma instituição de ensino pública e já existente, e por tal motivo não tem obrigatoriedade em cumprir a norma de desempenho de habitações, NBR 15575 (ABNT,2013). Porém, na falta desta a obrigatoriedade a administração do edifício deve seguir a cartilha do TCU, que recomenda que todos os órgãos públicos tenham um programa de manutenção com atividades pré-estabelecidas, incluindo inspeções com visitas para evitar ou amenizar patologias (TCU, 2014).

Entende-se que por se tratar de uma instituição pública a EM fica sujeita a processos licitatórios, muitas vezes morosos. Alia-se ao atual cenário econômico do país não demonstra uma política de fartos recursos para investimento em manutenção dos prédios públicos. Portanto faz-se necessário mudança no sistema de gestão de recursos públicos, uma vez que manutenções periódicas corretas podem evitar gastos futuros maiores, como correções de patologias de construção severas.

\section{AGRADECIMENTOS}

O presente trabalho foi realizado com apoio da Coordenação de Aperfeiçoamento de Pessoal de Nível Superior - Brasil (CAPES) - Código de Financiamento 001. Os autores também agradecem à FAPEMIG, CNPq, UFOP, IPHAN/Ouro Preto e Escola de Minas pelo apoio para a realização e apresentação dessa pesquisa. Somos gratos ainda pela infraestrutura e colaboração do Grupo de Pesquisa em Resíduos Sólidos - RECICLOS - CNPq e profissionais Fernando Murilo Gontijo 
Ramos, Antônio Maria Claret de Gouveia, Ernani Carlos de Araújo, José Augusto Nunes Nogueira, Pedro M. Gameiro Henriques, João Pedro Ramôa Correia, Tito Flávio R. de Aguiar, Bruno Trópia e Joana da Silva Vieira.

\section{REFERÊNCIAS}

ABNT NBR 14037- Diretrizes para elaboração de manuais de uso, operação e manutenção das edificações - Requisitos para elaboração e apresentação dos conteúdos. Rio de Janeiro, 2011.

ABNT NBR 15575- Edificações habitacionais — Desempenho Parte 1: Requisitos gerais. Rio de Janeiro, 2013.ABNT NBR 7200- Execução de revestimento de paredes e tetos de argamassas inorgânicas - Procedimento. Rio de Janeiro, 1998.

CASTRO, U. R. Importância da manutenção predial preventiva e as ferramentas para sua execução. Monografia. Curso de Especialização em Construção Civil. Universidade Federal de Minas Gerais, 2007, 44f.

DARDENGO, C. F. R. Identificação de patologias e proposição de diretrizes de manutenção preventiva em edifícios residenciais multifamiliares da cidade de viçosa - MG. Universidade Federal de Vicosa. Viçosa. 2010. Dissertação de pos graduação em engenharia civil.

GUIMARÃES, G. B. Desenvolvimento de sistema de indicadores para a gestão da manutenção de edifício público. 2018. 94 f. Dissertação (Mestrado em Administração Pública em Rede Nacional) - Universidade Federal de Goiás, Goiânia, 2018.

LEMOS, P. (. ). A História da Escola de Minas. 2ª edição. ed. Ouro Preto: Livraria \& Editora Graphar, 2013.501 p.

MACEDO A. T.. Avaliação do tratamento de trincas na recuperação de revestimentos de fachada. Centro Universitário de Brasília, Brasília,2018. Dissertação de pos graduação ECI - Pós-graduação em Projeto, Execução e Manutenção de Edificações

NEVES, Daniel R. R., BRANCO, Luiz Antônio M. N. Estratégia de Inspeção Predial. Belo Horizonte: Construindo, v.1, n.2, p. 12-19, jul./dez. 2009.

SOUZA, V.; RIPPER, T. Patologia, Recuperação e Reforço de Estruturas de Concreto. São Paulo: Pini, 1998.

TCU. $4^{\text {a }}$ Edição da Cartilha de Recomendaçoes Básicas para contratação e fiscalização de Obras Públicas de Edificações.

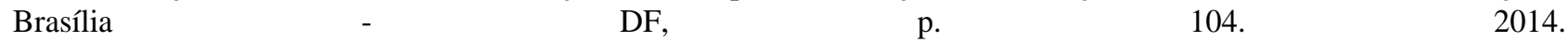
https://portal.tcu.gov.br/lumis/portal/file/fileDownload.jsp?fileId=8A8182A15232A37901529D259F061157.

UFOP. Projeto Escola de Minas, Ouro Preto, Março 1993.

UFOP. História da Escola de Minas. http: //www.em2.ufop.br, 2017. Disponivel em: <http://www.em2.ufop.br/index.php/historia>. Acesso em: junho 2017.

VILLANUEVA, M. M. A importância as manutenção preventiva para o bom desempenho da edificação Universidade Federal do Rio de janeiro / Escola Politécnica, 2015. 